\title{
Obesity indicators by race/ethnicity for diagnosis of cardiometabolic diseases for a US representative sample of adults
}

\author{
Joan A. Vaccaro ${ }^{1 *}$ and Fatma G. Huffman ${ }^{1}$ \\ *Correspondence: jvaccaro@fiu.edu \\ ${ }^{1}$ Florida International University, Robert R. Stempel College of Public Health and Social Work, Department of Dietetics and Nutrition, \\ Miami, Florida, USA.
}

\begin{abstract}
Background: Obesity, a growing epidemic, is a preventable risk factor for cardiometabolic diseases. Obesity and cardiometabolic diseases affect Hispanics and African Americans more than non-Hispanic Caucasians. This study examined the relationship among race/ethnicity, obesity diagnostic measures (body mass index, waist circumference, subscapular and triceps skinfold thickness), and cardiometabolic risk factors (hyperglycemia, high, non-high-density lipoprotein cholesterol, low, high-density lipoprotein cholesterol, and hypertension) for adults across the United States.

Methods: Using data from two-cycles of the National Health and Examination Survey (NHANES) 2007-2010, and accounting for the complex sample design, logistic regression models were conducted comparing obesity indicators in Mexican Americans, other Hispanics, and Black non-Hispanics, with White non-Hispanics and their associations with the presence of cardiometabolic diseases.

$\underline{\text { Results: }}$ Differences by race/ethnicity were found for subscapular skinfold thickness and hyperglycemia. Waist circumference and subscapular skinfold were positively associated with the presence of hyperglycemia; dyslipidemia, and hypertension across race/ ethnicity, adjusting for age, gender, smoking, physical activity, education, income to poverty index, and health insurance. Race/ ethnicity did not influence the association of any obesity indicators with the tested cardiometabolic diseases. All obesity measures except triceps skinfold were associated with hyperglycemia.
\end{abstract}

Conclusions: We suggest that subscapular skinfold thickness be considered as an inexpensive non-intrusive screening tool for cardiometabolic risk factors in an adult US population.

Keywords: Cardiovascular diseases, diabetes, hyperglycemia, hypertension, dyslipidemia, obesity, skinfold measures, race/ethnicity

\section{Introduction}

Obesity, $20 \%$ or more over ideal body weight, is a growing epidemic across race/ethnicity in the United States. From 1960-2006, the percentage of obese adults more than doubled, increasing from $13 \%$ to $35 \%$ [1]. Although there was not an increase in obesity from 2007 to 2010 [2,3], there are subpopulations whose rates exceeded the average. The prevalence of obesity is higher in African Americans (1.4) and Hispanics (1.2) as compared to non-Hispanic Whites [4]. Obesity has been clinically defined by several measures, including waist circumference and body mass index (BMI). Individuals whose body mass index $(\mathrm{BMI}) \geq 30 \mathrm{~kg} / \mathrm{m}^{2}$ are considered obese $[3,5]$. Based on a recent systematic meta-analysis of US and international populations, obese individuals were significantly were associated with higher mortality as compared to normal weight individuals [6]. (Flegal et al., 2013). Cardiometabolic risk is considered with waist circumference $\geq 102 \mathrm{~cm}$ ( $\geq 40$ in) for men and $\geq 88 \mathrm{~cm}$ ( $\geq 35 \mathrm{in}$ ) for women; however, there is evidence that these cutoffs may be lower in certain races/ethnicities [7]. Truncal skinfold thickness and waist circumference measures are considered indicators of central obesity. Skinfold thickness has been associated with body fatness and may be a better indicator of adverse health outcomes than BMI [8].
Obesity is among the major risk factors of cardiometabolic diseases including hyperglycemia (prediabetes/diabetes), hypertension and dyslipidemia [9]. Over one-quarter of a million premature deaths in the US per year are attributed to obesity [10]. The incidence of heart diseases, including diabetes, hypertension, and dyslipidemia, is greater for persons who are obese [10]. Early diagnosis and treatment depends on access to healthcare and uninsured persons are less-likely to receive medical care [11]. A higher percent of African Americans (20.8) and Hispanics (30.7) have no health insurance as compared to non-Hispanic Whites (11.7) [4]. Obesity screening methods for hard to reach population have not been determined. Health fairs and community health screenings with subscapular and triceps skinfold measurement may be more effective than taking weight, height and waist circumference. The purpose of this study is to assess the association of these obesity indicators with cardiometabolic diseases: hyperglycemia, hypertension, and high, non-high-density lipoprotein cholesterol (non-HDL-C), and low, high-density lipoprotein cholesterol (HDL-C).

\section{Materials and methods \\ Source of data}

Data for this study were from appended 2-year cycles of datasets 
Vaccaro et al. Cardiovascular System 2013,

from the National Health and Nutrition Examination Survey (NHANES) 2007-2008 and 2009-2010 [12]. NHANES uses a complex, multistage, probability sample design to obtain representative samples of the noninstitutionalized, civilian US population [12]. This study acquired data $(N=11,377)$ for males and females $\geq 21$ years of aged from four out of five racial/ethnic categories: Mexican Americans (MA); Other Hispanics (OH); Black non-Hispanics (BNH); and White nonHispanics (WNH). The classification 'other races' (Asian and mixed-races) was excluded since numbers in this category were not sufficient for multiple comparisons. The final sample size with data for the study variables was $N=8850$ (MA=1654, $\mathrm{OH}=1010, \mathrm{BNH}=1591$, $\mathrm{WNH}=4595$ ).

\section{Ethical considerations}

The data used for this study were publically available. Prior to public release, the study protocols (continuation of protocol \#2005-06 for both datasets) were approved by the National Center for Health Statistics Research Ethics Review Board (NCHS-ERB) [13]. Separate informed consent forms were signed by participants for the interview and health examination, or just the interview. Participants for this study read, understood, and signed informed consent forms for the interview and health examination.

\section{Major variables}

Independent variables included race/ethnicity and obesity indicators. A nominal category for race/ethnicity recoded for WNH as the reference. The category "other races" was eliminated with a filter. Waist circumference was tested for linearity and used as a continuous variable. Body mass index (BMI) was coded as an ordinal variable with four levels combining the World Health Organization (WHO)'s categories [5] as follows: underweight and normal were collapsed to category $1\left(\mathrm{BMl}<25 \mathrm{~kg} / \mathrm{m}^{2}\right)$; category 2 corresponded to pre obese $\left(\mathrm{BMI}=25-29.9 \mathrm{~kg} / \mathrm{m}^{2}\right)$; category 3 corresponded to obese, class I (BMI $\left.=30-34.9 \mathrm{~kg} / \mathrm{m}^{2}\right)$; and, category 4 combined obese classes II and III (BMI $\left.\geq 35 \mathrm{~kg} / \mathrm{m}^{2}\right)$. Waist circumference and skinfold thickness measurements, including triceps and subscapular, were categorized in quartiles. Dependent variables were prediabetes or diabetes, dyslipidemia, and hypertension. The variable for hyperglycemia was computed by $\%$ glycated hemoglobin $(\mathrm{A} 1 \mathrm{C}) \geq 6.0$, dyslipidemia, abnormal levels of one or more of the lipoproteins, was measured by low HDL-C and high, non-HDL-C $\geq 130 \mathrm{mg} / \mathrm{dL}$. Cutoffs for low $\mathrm{HDL}-\mathrm{C}$ were $<40 \mathrm{mg} / \mathrm{dL}$ for men and $<50 \mathrm{mg} / \mathrm{dL}$ for women [14]. The variable for non-HDL-C was created by subtracting $\mathrm{HDL}-\mathrm{C}$ from total cholesterol, then computing the binary variable. The American Association of Clinical Endocrinologists (AACE) recommend non-HDL-C be less than $30 \mathrm{mg} / \mathrm{dL}$ above the target for low-density lipoprotein cholesterol (LDL-C $<100$ $\mathrm{mg} / \mathrm{dL}$ ) [14]. Non-HDL-C is the sum of all lipoproteins except $\mathrm{HDL}-\mathrm{C}$ and includes LDL-C intermediate and very low-density lipoproteins, lipoprotein (a). A dyslipidemia score was created adding variables for high non-HDL-C, high triglycerides $(\geq 150$ $\mathrm{mg} / \mathrm{dL}$ ), and low, $\mathrm{HDL}$ ( $<40 \mathrm{mg} / \mathrm{dL}$ for men and $<50 \mathrm{mg} / \mathrm{dL}$ for women). A score of $\geq 1$ was considered having dyslipidemia. Hypertension was computed as a binary variable where systolic blood pressure $\geq 140 \mathrm{mmHg}$ or diastolic blood pressure $\geq 90 \mathrm{mmHg}$.

\section{Adjustment variables}

Clinically significant covariates and potential confounders were tested with Pearson's and Spearmen Rho's correlations. All variables were retained for full models except marital status. Categories for education were collapsed to three: < high school, high school, $>$ high school to assure sufficient power based on the estimated marginal means. A variable for physical activity: moderate or vigorous physical activity was computed by adding the yes and no responses for each category, then forming a binary variable for engaging in either moderate or vigorous physical activity. The income to poverty index was used to adjust for income. Health insurance was measured as a binary variable (yes/no). Smoking status was collapse to a binary variable, currently smoking (yes/no). In addition, variables for, gender (binary) and age in years (continuous) were used from the dataset.

\section{Statistical analysis}

The general characteristics of the study population by race/ ethnicity were determined using complex sample design logistic regression models for categorical variables and general linear models for continuous variables with WNH as the reference group. Reduced and full logistic regression models were performed for each cardiometabolic risk factor. Reduced models included 1- and 2-way interactions of race/ ethnicity with each obesity indicator and were adjusted by age and gender. When no interaction was present, the 2-way term was dropped to achieve optimal model fit. Full models included the covariates of the reduced models along with currently smoking, education, health insurance, income to poverty index, and physical activity. Adjusted sample weights were used to account for unequal probabilities of selection and nonresponse in the multistage stratified cluster sampling design used in NHANES to achieve unbiased national estimates. The sample weights used were based on the Mobile Examination Center (MEC) and were computed using the average of the 2-year sample weights for each cycle, as per guidelines set by NHANES $[12,15]$. Data analysis was conducted with the complex sampling module, IBM-SPSS version 20 . The Wald $F$ statistic was used to determine model significance for logistic regression analysis [16]. A $P$-value of $<.05$ was considered significant.

\section{Results}

Risk factors associated with obesity and obesity indicators by race/ethnicity are depicted in (Table 1). Compared to WNH, other racial/ethnic groups were younger, had lower incomes, 
Vaccaro et al. Cardiovascular System 2013,

http://www.hoajonline.com/journals/pdf/2052-4358-1-4.pdf

doi: $10.7243 / 2052-4358-1-4$

Table 1. Major cardiometabolic risk factors of the study population by race/ethnicity.

\begin{tabular}{|c|c|c|c|c|c|}
\hline Variable & MA & $\mathrm{OH}$ & BNH & WNH reference & $P$-value \\
\hline \multicolumn{6}{|l|}{ Continuous variables - mean (SE) } \\
\hline Age (years) & $40.9(0.65)^{* *}$ & $42.2(0.71)^{* *}$ & $45.0(0.59)^{\star *}$ & $49.2(0.37)$ & $<.001$ \\
\hline Income to poverty index & $1.84(0.05)^{* *}$ & $2.07(0.07)^{\star \star}$ & $2.34(0.08)^{\star * *}$ & $3.32(0.07)$ & $<.001$ \\
\hline Glycated hemoglobin (\%) & $5.71(0.04)^{*}$ & $5.65(0.04)$ & $5.84(0.03)^{\star *}$ & $5.56(0.02)$ & $<.001$ \\
\hline Waist circumference $(\mathrm{cm})$ & $98.9(0.54)$ & $96.7(0.68)^{\star}$ & $99.7(0.53)$ & $98.7(0.37)$ & .016 \\
\hline Male $(\mathrm{cm})$ & $100.2(0.81)^{*}$ & $99.4(.94)^{*}$ & $98.3(0.62)^{*}$ & $102.5(0.42)$ & $<.001$ \\
\hline Female $(\mathrm{cm})$ & $97.5(0.47)^{*}$ & $94.2(0.76)$ & $100.9(0.70)^{\star *}$ & $95.1(0.49)$ & $<.001$ \\
\hline Triceps skinfold thickness (mm) & $19.0(0.34)$ & $19.4(0.38)$ & $20.5(0.29)^{*}$ & $19.3(0.20)$ & .003 \\
\hline Subscapular skinfold thickness (mm) & $22.5(0.31)^{\star *}$ & $22.3(0.34)^{\star \star}$ & $23.3(0.36)^{\star *}$ & $20.5(0.18)$ & $<.001$ \\
\hline \multicolumn{6}{|l|}{ Categorical variables - percent within race/ethnicity (SE) } \\
\hline Triceps $\left(75^{\text {th }} \%>25.5 \mathrm{~mm}\right)$ & $23.2(1.2)$ & $24.8(1.7)$ & $33.2(1.1)^{*}$ & $23.8(1.0)$ & $<.001$ \\
\hline Subscapular $\left(75^{\text {th }} \%>27.4 \mathrm{~mm}\right)$ & $26.4(1.6)^{\star \star}$ & $26.1(2.1)^{* *}$ & $35.9(1.6)^{* *}$ & $21.7(0.9)$ & $<.001$ \\
\hline Body mass index $\left(\mathrm{BMI} \geq 35 \mathrm{~kg} / \mathrm{m}^{2}\right)$ & $18.3(0.9)^{\star \star}$ & $17.3(1.4)$ & $26.1(1.2)^{* *}$ & $16.4(1.6)$ & $<.001$ \\
\hline Diabetes $(\mathrm{A} 1 \mathrm{C} \geq 6.5 \%)$ & $10.1(1.0)^{\star *}$ & $8.4(0.8)^{\star *}$ & $12.3(0.7)^{\star *}$ & $6.8(0.6)$ & $<.001$ \\
\hline Hyperglycemia (A1C $\geq 6.0 \%)$ & $18.4(1.2)^{*}$ & $16.9(1.3)$ & $26.6(1.3)^{* *}$ & $14.8(1.0)$ & $<.001$ \\
\hline High non-HDL-cholesterol ( $\geq 130 \mathrm{mg} / \mathrm{dL})$ & $33.6(1.3)^{*}$ & $36.4(1.8)$ & $45.7(1.3)^{* *}$ & $37.0(0.7)$ & $<.001$ \\
\hline Hypertension (yes) & $19.8(1.5)^{\star *}$ & $21.6(1.6)^{* *}$ & $39.5(1.3)^{* *}$ & $32.3(1.0)$ & $<.001$ \\
\hline Currently smoking (yes) & $22.5(1.2)^{\star \star}$ & $14.8(1.8)$ & $21.6(1.7)$ & 19.1(1.2) & .001 \\
\hline No health insurance & $51.4(1.8)^{\star \star}$ & $36.0(3.1)^{* *}$ & $25.7(1.4)^{* *}$ & $13.4(0.7)$ & $<.001$ \\
\hline Education $<$ high school & $51.9(1.6)^{\star *}$ & $37.6(2.4)^{\star *}$ & $26.1(1.8)^{\star *}$ & $13.7(1.4)$ & $<.001$ \\
\hline Engage in moderate or vigorous physical activity (yes) & $39.3(2.1)^{* *}$ & $41.3(1.7)^{* *}$ & $41.8(1.2)^{* *}$ & $54.7(2.3)$ & $<.001$ \\
\hline High sedentary activity $>4$ hours/day & $44.3(2.5)^{\star *}$ & $51.7(2.1)^{* *}$ & *65.9(1.8) & $72.8(1.2)$ & $<.001$ \\
\hline
\end{tabular}

Abbreviations: MA: Mexican American; OH: other Hispanic; BNH: Black non-Hispanic; WNH: White non-Hispanic; A1C: glycated hemoglobin (hemoglobin A1c).

Notes: Continuous variables were reported as weighted means (SE). Categorical variables were reported as population percent (SE). P-values test the differences by race/ethnicity by the Wald F-statistic; asterisk symbols denote significant differences of each race/ethnicity as compared to White non-Hispanics (WNH). Income to poverty index is based on a scale (0-5) where $0-1$ is below poverty, 1.0 is at poverty and other values measure relative distance from poverty. Non-HDL-cholesterol=non-high-density lipoprotein cholesterol. Pulse pressure was measured as the difference between the average systolic blood pressure and average diastolic blood pressure.

${ }^{*}=P<.05 ;{ }^{* *}=P<.001$.

less education and a higher prevalence of not having health insurance. WNH had a higher prevalence of engaging in moderate or vigorous physical activity, but spent more hours of sedentary activity as compared to other ethnic/racial groups. Obesity indicators had different patterns by race/ethnicity; however, subscapular skinfold thickness was significantly higher for all groups as compared to WHN. Diabetes and hypertension were more prevalent in all groups as compared to WNH. High A1C (prediabetes and diabetes) was more prevalent in $\mathrm{MA}$ and $\mathrm{BNH}$ as compared to $\mathrm{WNH}$. The percent of high non-HDL cholesterol was greater for MA and $\mathrm{BNH}$ as compared to WHN. The fully adjusted models maintained the same patterns as the reduced models.

Final reduced and fully adjusted logistic regression analyses (Models 1,2,3) for the effect of obesity indicator and race on cardiometabolic disease states are shown in (Table 2). There were differences by race for all cardiometabolic diseases tested; however, two-way interactions of race/ethnicity by each of the obesity indicators were not significant. Therefore, interactions are not presented in the final models. For each model, subscapular skinfold and waist circumference measures were significant obesity indicators associated with each cardiometabolic disease: hyperglycemia, dyslipidemia, and hypertension. BMI was associated with Model 1 (hyperglycemia), only. Triceps skinfold thickness was not a significant indicator for the diseases tested. For (Model 1), subscapular skinfold thickness at the lowest quartile was 2.63 times less likely to have high $\mathrm{A} 1 \mathrm{C}$ as compared to the highest quartile. The Odds Ratio for the lowest quartile subscapular skinfold thickness (0.38) represents the decrease in likelihood for high A1C as compared to the Odds Ratio of 1.00 for the highest quartile) (Model 1). Waist circumference had a stronger association with high $\mathrm{A} 1 \mathrm{C}$ than subscapular skinfold thickness (Model 1). The lowest quartile was 4.00 times less likely than the highest quartile to have high A1C (prediabetes or diabetes) (Model 1). BMI and triceps skinfold thickness were not significantly associated with high A1C (Model 1). Model 2 (reduced and fully adjusted), depicts those in the lowest quartiles of waist circumference and subscapular skinfold thickness were more likely to have high non HDL-C than those in the highest quartiles (see Table 2 legend notes). Since hypertension and hyperglycemia are commonly associated with dyslipidemia, additional analyses were conducted. (Table 3) presents the final models with Odds Ratios of race/ ethnicity and obesity indicators for two models of dyslipidemia, Model A, non-HDL-C and Model B, HDL-C. Both the reduced 
Vaccaro et al. Cardiovascular System 2013,

http://www.hoajonline.com/journals/pdf/2052-4358-1-4.pdf

Table 2. Likelihood for cardiometabolic diseases by race/ethnicity and obesity indicators.

\begin{tabular}{|c|c|c|c|}
\hline Dependent variables (disease state) & Independent variables (risk factors) & Reduced Models OR $(95 \% \mathrm{CI})$ & Full Models OR (95\% CI) \\
\hline Model 1. A1C $\geq 6.0$ & Race/ethnicity & $P<.001$ & $P<.001$ \\
\hline \multirow[t]{20}{*}{ (Hyperglycemia) } & MA & $2.58(1.94,3.44)$ & $1.94(1.39,2.72)$ \\
\hline & $\mathrm{OH}$ & $2.17(1.51,3.12)$ & $1.72(1.12,2.66)$ \\
\hline & $\mathrm{BNH}$ & $3.06(2.36,3.99)$ & $2.57(1.94,3.41)$ \\
\hline & WNH (reference) & 1.00 & 1.00 \\
\hline & Subscapular skinfold thickness & $P<.001$ & $P<.001$ \\
\hline & $25^{\text {th }}$ percentile & $0.38(0.29,0.52)$ & $0.34(0.26,0.45)$ \\
\hline & $50^{\text {th }}$ percentile & $0.49(0.39,0.60)$ & $0.47(0.38,0.58)$ \\
\hline & $75^{\text {th }}$ percentile & $0.72(0.57,0.92)$ & $0.68(0.51,0.90)$ \\
\hline & $>75^{\text {th }}$ percentile (reference) & 1.00 & 1.00 \\
\hline & Triceps skinfold thickness & ns $(P=.195)$ & ns $(P=.460)$ \\
\hline & BMI & $(P=.041)$ & $(P=.020)$ \\
\hline & $<25 \mathrm{~kg} / \mathrm{m}^{2}$ & $0.61(0.40,0.94)$ & $0.56(0.36,0.87)$ \\
\hline & $25-29.9 \mathrm{~kg} / \mathrm{m}^{2}$ & $0.60(0.43,0.84)$ & $0.57(0.41,0.79)$ \\
\hline & $30-34.9 \mathrm{~kg} / \mathrm{m}^{2}$ & $0.74(0.55,1.00)$ & $0.74(0.54,1.03)$ \\
\hline & $\geq 35 \mathrm{~kg} / \mathrm{m}^{2}$ (reference) & 1.00 & 1.00 \\
\hline & Waist circumference & $P<.001$ & $P<.001$ \\
\hline & $25^{\text {th }}$ percentile & $0.25(0.16,0.38)$ & $0.28(0.19,0.43)$ \\
\hline & $50^{\text {th }}$ percentile & $0.52(0.39,0.68)$ & $0.57(0.42,0.76)$ \\
\hline & $75^{\text {th }}$ percentile & $0.64(0.50,0.82)$ & $0.68(0.51,0.90)$ \\
\hline & $>75^{\text {th }}$ percentile (reference) & 1.00 & 1.00 \\
\hline Model 2. Non-HDL-C $\geq 130 \mathrm{mg} / \mathrm{dL}$ & Race/ethnicity & $P<.001$ & $P<.001$ \\
\hline \multirow[t]{16}{*}{ (Dyslipidemia) } & MA & $0.90(0.78,1.02)$ & $0.92(0.78,1.08)$ \\
\hline & $\mathrm{OH}$ & $1.02(0.83,1.26)$ & $1.03(0.83,1.27)$ \\
\hline & $\mathrm{BNH}$ & $1.57(1.34,1.84)$ & $1.59(1.34,1.88)$ \\
\hline & WNH (reference) & 1.00 & 1.00 \\
\hline & Subscapular skinfold thickness & $P<.001$ & $P<.001$ \\
\hline & 25th percentile & $1.81(1.38,2.37)$ & $1.80(1.37,2.38)$ \\
\hline & 50th percentile & $1.21(0.94,1.55)$ & $1.20(0.93,1.56)$ \\
\hline & 75th percent & $0.94(0.80,1.12)$ & $1.59(1.34,1.88)$ \\
\hline & $>75$ th percent (reference) & 1.00 & 1.00 \\
\hline & Triceps skinfold thickness & ns $(P=.432)$ & ns $(P=.456)$ \\
\hline & BMI $(\mathrm{kg} / \mathrm{m} 2)$ & ns $P=.074$ & ns $P=.062$ \\
\hline & Waist circumference & $P<.001$ & $P<.001$ \\
\hline & 25th percentile & $1.55(1.12,2.13)$ & $1.51(1.09,2.10)$ \\
\hline & 50th percentile & $0.84(0.61,1.15)$ & $0.83(0.61,1.14)$ \\
\hline & 75th percentile & $0.77(0.63,0.95)$ & $0.76(0.62,0.94)$ \\
\hline & $>75$ th percentile (reference) & 1.00 & 1.00 \\
\hline
\end{tabular}

MA: Mexican American; OH: other Hispanic; BNH: Black non-Hispanic; WNH: White non-Hispanic; A1C: glycated hemoglobin (hemoglobin A1c); BMI: body mass index.

Notes: Reduced models included race/ethnicity and obesity indicators, and were adjusted for age and gender; full models included variables in the reduce model with additional adjustments for smoking, health insurance, education, income to poverty index, and physical activity. Model 2 suggests possible confounders, such as cholesterol-lowing medications, and individual variation may have influenced the relationship of level of obesity and presents of high non-HDL-C. Cholesterol medication variables were available not for the entire sample. A model was run with this limited sample $(n=2317)$. The adjustment did not change the direction of obesity indicators; the lowest quartiles of obesity indicator were still associated with an increased likelihood of high non-HDL-C.

models and fully adjusted models include two measures of cardiometabolic diseases associated with dyslipidemia, hyperglycemia and hypertension. There were significant differences by race/ethnicity for these dyslipidemia indicators; however, the two-way interactions for race/ethnicity by each obesity indicator were not significant for both models. Therefore, interactions are not presented in the final models. Models with dyslipidemia measured as having at least one of the following: high non-HDL-C, low HDL-C, or high triglycerides did not achieve adequate fit and classification. This may 
Vaccaro et al. Cardiovascular System 2013,

http://www.hoajonline.com/journals/pdf/2052-4358-1-4.pdf

doi: $10.7243 / 2052-4358-1-4$

Table 2 (continued). Likelihood for cardiometabolic diseases by race/ethnicity and obesity indicators.

\begin{tabular}{llll}
\hline Dependent variables (disease state) & Independent variables (risk factors) & Reduced Models OR (95\% CI) & Full Models OR (95\% CI) \\
\hline Model 3. SBP $\geq 140$ or DBP $\geq 90$ & Race/ethnicity & $P<.001$ & $P<.001$ \\
mmHg (Hypertension ) & MA & $0.86(0.70,1.04)$ & $0.81(0.65,1.01)$ \\
OH & $0.84(0.69,1.01)$ & $0.80(0.64,0.99$ \\
BNH & $2.14,1.73,2.64)$ & $2.03(1.66,1.48)$ \\
WNH (reference) & 1.00 & 1.00 \\
Subscapular skinfold thickness & $P=.001$ & $0.001(0.51,0.80)$ \\
25th percentile & $0.64(0.52,0.80)$ & $0.78(0.64,0.94)$ \\
50th percentile & $0.78(0.64,0.95)$ & $0.96(0.79,1.17)$ \\
75th percentile & $0.97(0.79,1.18)$ & 1.00 \\
>75th percent (reference) & 1.00 & $\mathrm{~ns} P=.338$ \\
Triceps skinfold thickness & $\mathrm{ns} P=.264$ & $\mathrm{~ns} P=.062$ \\
BMI & $\mathrm{ns} \mathrm{P}=.074$ & $P<.001$ \\
Waist circumference & $P<.001$ & $0.44(0.32,0.61)$ \\
25th percentile & $0.42(0.30,0.59)$ & $0.64(046,0.90)$ \\
50th percentile & $0.62(0.43,0.88)$ & $0.83(0.61,1.12)$ \\
\hline
\end{tabular}

MA: Mexican American; OH: other Hispanic; BNH: Black non-Hispanic; WNH: White non-Hispanic; A1C: glycated hemoglobin (hemoglobin A1c.); BMI: body mass index.

Notes: Reduced models included race/ethnicity and obesity indicators, and were adjusted for age and gender; full models included variables in the reduce model with additional adjustments for smoking, health insurance, education, income to poverty index, and physical activity.

be due, in part, to the high percent of missing values for triglycerides. In addition, separate model were run for men and women for each measure of dyslipidemia; however, the patterns of significance were the same as for the combined model (data not shown).

Separate models of dyslipidemia measures (Models A and B) were conducted (Table 3 ). For Model A, individuals with hyperglycemia were more likely to have high non-HDL-C in both the reduced $[\mathrm{OR}=1.57(1.34,1.83)]$ and the fully adjusted $[\mathrm{OR}=1.60(1.37,1.88]$ models. The Odds Ratios for high non$\mathrm{HDL}-\mathrm{C}$ for persons with hypertension were greater than for people without hypertension in the reduced $[1.25(1.06,1.47)]$ and fully adjusted $[1.24(1.06,1.46)]$ models. BNH had a higher Odds Ratio of high non-HDL-C as compared to WNH in the reduced $[1.45(1.24,1.71)]$ and fully adjusted $[1.49(1.25,1.76)]$ models. Individuals in the lowest quartile of subscapular skinfold thickness were more likely to have high non-HDL-C as compared to those in the highest quartile in the reduced $[O R=1.89(1.45,2.47)]$ and fully adjusted $[O R=1.90(1.44,2.49)]$ models. This unexpected, inverse relationship was found for waist circumference, as well, where the $1^{\text {st }}$ quartile was more likely to have high non-HDL-C as compared to the $4^{\text {th }}$ quartile for the reduced $[O R=1.70(1.22,2.36)]$ and fully adjusted $[\mathrm{OR}=1.65(1.19,2.30)]$ models. For Model B, low HDL-C, individuals with hyperglycemia were more likely to have low HDL-C in both the reduced $[\mathrm{OR}=1.98(1.62,1.78)]$ and fully adjusted $[O R=1.78(1.47,2.16)]$ models as compared to those with normal A1C. Low HDL-C was more likely for those with as compared to without hypertension for the reduced $[O R=1.23(1.05,1.45)]$ and fully adjusted $[O R=1.21(1.03,1.43)]$ models. BNH were less-likely to have low HDL-C as compared to $W H N$ in the reduced $[\mathrm{OR}=0.53(0.42,0.66)]$ and fully adjusted $[\mathrm{OR}=0.43(0.34,0.55)]$ models. Individuals of normal BMI's were significantly less likely to have low HDL-C than those with BMI's $\geq 35 \mathrm{~kg} / \mathrm{m}^{2}$. Persons with waist circumference in the $25^{\text {th }}$ and $50^{\text {th }}$ percentiles were less likely to have low HDL-C as compared to the highest quartile $\left(>75^{\text {th }}\right)$. Triceps skinfold thickness was not significant for any model and BMI was only significant in the fully adjusted model for HDL-C.

\section{Discussion}

Subscapular skinfold thickness and waist circumference were both significantly associated with hyperglycemia, dyslipidemia, and hypertension, independent of race/ethnicity. BMI was related to hyperglycemia, only. Triceps skinfold thickness was not associated with any of the cardiometabolic diseases. Adults in the under- and normal-weight categories were more likely to have high non-HDL-C. The findings suggest that obesity indicators may be an ineffective method of screening for dyslipidemia in normal weight adults.

Additionally, our findings reconfirm racial/ethnic health disparities are still prevalent in the US. We found BNH to have the highest odds of having prediabetes/diabetes, dyslipidemia, and hypertension, as compared to WNH adjusting for obesity and sociodemographics. All groups ( $\mathrm{MA}, \mathrm{OH}$, and $\mathrm{BNH}$ ) had higher odds of prediabetes/diabetes as compared to WNH, adjusting for obesity and sociodemographics. Our results suggests measures of central obesity, such as waist circumference and subscapular skinfold measurements, are better indicators of cardiometabolic diseases than BMI or peripheral obesity (measured by triceps skinfold thickness) for a representative national sample of US adults across race/ 
Vaccaro et al. Cardiovascular System 2013,

http://www.hoajonline.com/journals/pdf/2052-4358-1-4.pdf

doi: $10.7243 / 2052-4358-1-4$

Table 3. Effect of obesity indicators with hyperglycemia and hypertension on dyslipidemia.

\begin{tabular}{|c|c|c|c|c|}
\hline \multirow{2}{*}{$\begin{array}{l}\text { Models } A \text { and } B \\
\text { Independent variables }\end{array}$} & \multicolumn{2}{|c|}{ A. Dependent variable: high, non- $H D L-C$} & \multicolumn{2}{|c|}{ B. Dependent variable: low, $H D L-C$} \\
\hline & Reduced Model OR (95\% CI) & Full Model OR (95\% CI) & Reduced Model OR (95\% CI) & Full Model OR (95\% CI) \\
\hline Hyperglycemia & $1.57(1.34,1.83)$ & $1.60(1.37,1.88)$ & $1.98(1.62,2.42)$ & $1.78(1.47,2.16)$ \\
\hline Hypertension & $1.25(1.06,1.47)$ & $1.24(1.06,1.46)$ & $1.23(1.05,1.45)$ & $1.21(1.03,1.43)$ \\
\hline Race/ethnicity & $P<.001$ & $P<.001$ & $P<.001$ & $P<.001$ \\
\hline MA & $0.86(0.076,0.99)$ & $0.91(0.78,1.07)$ & $1.13(0.88,2.46)$ & $0.93(0.70,1.23)$ \\
\hline $\mathrm{OH}$ & $0.99(0.79,1.23)$ & $1.00(0.81,1.25)$ & $0.98(0.80,2.21)$ & $0.81(0.66,0.99)$ \\
\hline $\mathrm{BNH}$ & $1.45(1.24,1.71)$ & $1.49(1.25,1.76)$ & $0.53(0.42,0.66)$ & $0.43(0.34,0.55)$ \\
\hline WNH (reference) & 1.00 & 1.00 & 1.00 & 1.00 \\
\hline Subscapular skinfold thickness & $P<.001$ & $P<.001$ & $P<.001$ & $P<.001$ \\
\hline $25^{\text {th }}$ percentile & $1.89(1.45,2.47)$ & $1.90(1.44,2.49)$ & $0.48(0.36,0.63)$ & $0.42(0.32,0.57)$ \\
\hline $50^{\text {th }}$ percentile & $1.25(0.97,1.60)$ & $1.25(0.97,1.61)$ & $0.67(0.56,0.80)$ & $0.64(0.53,0.76)$ \\
\hline $75^{\text {th }}$ percentile & $0.96(0.81,1.13)$ & $0.96(0.81,1.14)$ & $0.85(0.72,1.02)$ & $0.82(0.69,0.98)$ \\
\hline$>75^{\text {th }}$ percentile (reference) & 1.00 & 1.00 & 1.00 & 1.00 \\
\hline Triceps skinfold thickness & ns $P=.244$ & ns $P=.195$ & ns $P=.887$ & ns $P=.529$ \\
\hline $\operatorname{BMI}\left(\mathrm{kg} / \mathrm{m}^{2}\right)$ & ns $P=.377$ & ns $P=.423$ & ns $P=.151$ & $P=.015$ \\
\hline$<25 \mathrm{~kg} / \mathrm{m}^{2}$ & - & - & - & $0.61(0.44,0.85)$ \\
\hline $25-29.9 \mathrm{~kg} / \mathrm{m}^{2}$ & - & - & - & $0.78(0.60,1.02)$ \\
\hline $30-34.9 \mathrm{~kg} / \mathrm{m}^{2}$ & - & - & - & $0.88(0.67,1.18)$ \\
\hline$\geq 35 \mathrm{~kg} / \mathrm{m}^{2}$ (reference) & - & - & - & 1.00 \\
\hline Waist circumference & $P<.001$ & $P<.001$ & $P<.001$ & $P<.001$ \\
\hline $25^{\text {th }}$ percentile & $1.70(1.22,2.36)$ & $1.65(1.19,2.30)$ & $0.44(0.30,0.63)$ & $0.54(0.38,0.76)$ \\
\hline $50^{\text {th }}$ percentile & $0.90(0.66,1.24)$ & $0.89(0.65,1.22)$ & $0.62(0.44,0.88)$ & $0.71(0.52,0.97)$ \\
\hline $75^{\text {th }}$ percentile & $0.81(0.66,0.99)$ & $0.80(0.65,0.99)$ & $0.91(0.70,1.18)$ & $0.98(0.76,1.26)$ \\
\hline$>75^{\text {th }}$ percentile (reference) & 1.00 & 1.00 & 1.00 & 1.00 \\
\hline
\end{tabular}

Abbreviations: MA: Mexican American; OH: other Hispanic; BNH: Black non-Hispanic; WNH: White non-Hispanic; A1C: glycated hemoglobin (hemoglobin A1c); BMI: body mass index.

Notes: Reduced models included prediabetes/diabetes ( $11 \mathrm{C} \geq 6.0$ ), hypertension ( $\mathrm{SBP} \geq 140$ or $\mathrm{DBP} \geq 90 \mathrm{mmHg}$ )

race/ethnicity and obesity indicators, and were adjusted for age and gender; full models included variables in the reduce model with additional adjustments for smoking, health insurance, education, income to poverty index, and physical activity.

ethnicity. However, caution needs to be exercises when using obesity indicators screening for dyslipidemia.

The obesity indicator that is most useful in screening adults for risk of diabetes, hypertension, and dyslipidemia has not been established. There is no concordance in the literature for an obesity indicator specific for each racial/ethnic group. Whether BMI or central obesity measures are more suitable indicators of CVD risk remains an area of disagreement. In a combined analysis of four longitudinal studies of Caucasians, there was no difference in central obesity compared to BMI in predicting diabetes and heart disease [17]. These results may not be applicable to Blacks and Hispanics. For example, Mackay et al., [18] found obesity indicators for African Americans to differ as compared to Hispanics and WNH using area under the receiver operating characteristic (AROC) curve (c-statistic) [18]. While central and overall obesity predicted the 5-year incidence of diabetes for other racial/ethnic groups, only central obesity predicted the incidence of diabetes for African Americans [18]. The investigators found subscapular to triceps ratio was the most predictive of diabetes for African
Americans; while BMI was most predictive of diabetes for Hispanics and WNH [18]. Misra et al., [19] reviewed average values of waist circumference with associated CVD risk and found differences in optimal cutoff points by race/ethnicity. The authors attribute these differences to race/ethnic determinants of abdominal tissue that are influenced by the distribution of skeletal muscle, body fat, and bone [19]. For a population of multiracial children, combined CVD risk factors (serum lipids, fasting insulin, and blood pressure) prevalence was predicted by both $\mathrm{BMI}$ and skinfold sum (triceps and scapular) equally for the $85-94^{\text {th }}$ percentile; albeit, the investigators noted BMI had a higher ratio for the comparison of $\geq 95^{\text {th }}$ versus $<25^{\text {th }}$ percentiles [8]. Schubert et al., [20] reported that for adults, BMI, without bioelectric impedance correction, does not distinguish between fat and fat-free mass. In their longitudinal study of men and women, aged 40-60 years, there were significant increases in total cholesterol, low-density cholesterol, and triglycerides as fat-mass increased [20].

Skinfold thickness measurements have also been considered as an obesity indicator and markers for CVD risk including 
prediabetes and diabetes. In a review of obesity indicators of CVD risk, Snijder et al., [21] considered subscapular skinfold thickness to be a promising, simple indicator of central obesity citing several studies that found associations of skinfold thickness with high blood pressure and dyslipidemia. In a cohort of men, incidence of coronary heart disease after a 12 year follow-up was associated with subscapular skinfold thickness, independent of BMI and adjusting for confounders [22]. Subscapular skinfold thickness, a measure of fat mass, was found to be a better predictor of CVD risk in cluster analysis as compared to BMI for Asian Indian adolescents [23]. Truncal skinfold thickness (subscapular, iliac and abdominal measures summed) was the sole predictor of plasma insulin after oral glucose tolerance test for adults across BMI categories for adults with prediabetes and diabetes [24]. The investigators recommend the use of skinfold thickness measure in screening for abnormal glucose or insulin [24]. Subscapular skinfold thickness, as compared to other obesity indicators (BMI, waist to hip ratio, waist circumference, abdominal measures, and other skinfold thickness measurements) was significantly higher for those with persistent impaired glucose tolerance (prediabetes) [25].

Our results indicating that obesity indicators may not be suitable for dyslipidemia screening have been supported by the literature. Low-density lipoprotein cholesterol (LDL-C) was not significantly associated with subcutaneous fat in normal weight Caucasian adults, neither for males nor for female [26]. The investigators found associations with visceral, but not subcutaneous fat related to blood lipids [26]. Kim et al., [27] found controlling for waist circumference did not influence the positive association between body fat mass and cardiometabolic risk factors (hyperglycemia and dyslipidemia) for Korean adults of normal body weight (measured by BMI adjusted for Asian body type). There were no significant prevalence rates for diabetes, hypertension, and dyslipidemia according to increasing $\mathrm{BMI} \geq 35 \mathrm{~kg} / \mathrm{m}^{2}$ for African Americans, adjusting for age and gender [28]. The authors suggest a lower range of $\mathrm{BMI}\left(30-34 \mathrm{~kg} / \mathrm{m}^{2}\right)$ may be expected for the likelihood of higher rates of these diseases [28].

This study has several strengths and weaknesses and the results should be interpreted in their context. A major strength of this investigation was the use of a large, nationally representative dataset. Another benefit of this study was the current comparison of minorities to WNH in areas of cardiometabolic risk factors with and without sociodemographic adjustments. Although efforts have been made to reduce health disparities, prevalence of health outcomes by race/ethnicity needs to be assessed every few years. The outcome chosen for race/ethnicity and obesity markers, non-HDL-C, may better reflect cardiometabolic risk than LDL-C according to a review by [29]. Several limitations were noted. The category "other races" was not used, due to a small sample size. Several variables were not used to adjust for individual differences. Atherogenic dyslipidemia, which includes small-dense LDL particles, was not measured; albeit non-HDL-C has been found to correlate more strongly with two indicators of atherogenic dyslipidemia, apoprotein (a) and small dense LDL particles [29]. Another limitation of this study was that cholesterol-lowering medication use was not available for the complete sample; however, in an analysis of the subsample where medication use was available, the pattern of significance was the same with or without this adjustment. Additionally, family history of high cholesterol was not available and may have been a confounder with obesity for non-HDL-C but not for HDL-C. The effect of obesity indicators in these dyslipidemia outcomes may be attributed to the fact that statins and other cholesterol medications seldom achieve improvement in HDL-C [30].

\section{Conclusions}

Although obesity indicators and cardiometabolic diseases differed by race/ethnicity; the effect of obesity indicators on these diseases were not influenced by race/ethnicity. Subscapular skinfold thickness and waist circumference, measures of central obesity, were positively associated with hyperglycemia, hypertension, and one measure of dyslipidemia, low-HDL. Conversely, both subscapular skin fold thickness and waist circumference had an inverse association with non-HDL-C, suggesting the presence of confounders. $\mathrm{BMI}$ was positively associated with hyperglycemia; however, relationships with non-HDL-C and HDL-C reduced models were not significant. There was a weak association of BMI and HDL-C in the fully adjusted model. Triceps skinfold thickness, a measure of peripheral body fat, was not associated with any of the assessed cardiometabolic disease. Subscapular skinfold measure should be considered as part of a screening for cardiometabolic diseases for adults in the US population.

\section{Competing interests}

The authors declare that they have no competing interests.

\section{Authors' contributions}

Joan A. Vaccaro and Fatma G. Huffman participated equally to the concept and design of the work. Joan A. Vaccaro performed the data acquisition and analysis and wrote the initial draft. Fatma G. Huffman critically reviewed and revised the manuscript. Both authors approved the final version.

\section{Publication history}

Received: 01-Mar-2013 Revised: 14-Apr-2013

Accepted: 19-Apr-2013 Published: 23-Apr-2013

\section{References}

1. CDC, 2010. Health United States, 2009. (page 7). I Pdf

2. C. L. Ogden, M. D. Carroll, B. K. Kit, and K. M. Flegal: Prevalence of obesity in the United States, 2009-2010. NCHS Data Brief, No. 82, January, 2012. | Website

3. Center for Disease Control and Prevention (CDC): Obesity and overweight for professionals: adults defining, Updated, April 37, 2012. Website

4. Office of Minority Health (OMH): US Department of Health and Human 
Vaccaro et al. Cardiovascular System 2013,

Services. | Website

5. The World Health Organization (WHO): Global database on body mass index. Obesity and overweight, fact sheet no. 311, May, 2012.| Website

6. Flegal KM, Kit BK, Orpana $\mathrm{H}$ and Graubard BI: Association of all-cause mortality with overweight and obesity using standard body mass index categories: a systematic review and meta-analysis. JAMA 2013, 309:71-82. | Article | PubMed

7. Grundy SM, Cleeman JI, Daniels SR, Donato KA, Eckel RH, Franklin BA, Gordon DJ, Krauss RM, Savage PJ, Smith SC, Jr., Spertus JA and Costa F: Diagnosis and management of the metabolic syndrome: an American Heart Association/National Heart, Lung, and Blood Institute Scientific Statement. Circulation 2005, 112:2735-52. | Article | PubMed

8. Freedman DS, Katzmarzyk PT, Dietz WH, Srinivasan SR and Berenson GS: Relation of body mass index and skinfold thicknesses to cardiovascular disease risk factors in children: the Bogalusa Heart Study. Am J Clin Nutr 2009, 90:210-6. | Article I PubMed Abstract | PubMed Full Text

9. Eckel RH, Kahn R, Robertson RM and Rizza RA: Preventing cardiovascular disease and diabetes: a call to action from the American Diabetes Association and the American Heart Association. Circulation 2006, 113:2943-6. I Article I PubMed

10. Surgeon General: Overweight and obesity: Health consequences. | Website

11. Healthy People, 2020: Access to Health Services. I Website

12. National Center Health Statistics: National Health and Nutrition Examination survey, questionnaires, datasets and related documentation.

13. NCHS Research Ethics Review Board (ERB): Approval National Health and Nutrition Examination, National Center of Health Statistics (NHANES-NCHS), NCHS Research Ethnics Review Board (ERB) Approval. | Website

14. American Association of Clinical Endocrinologists' (AACE): Guidelines for management of dyslipidemia and prevention of atherosclerosis. Endocr Pract 2012, 18(suppl. 1). I Pdf

15. National Center for Health Statistics (NCHS): Center for Disease Control and Prevention. National Health and Nutrition Examination Survey (NHANES), Analytical and Reporting Guidelines. Hyattsville, MD, USA, 2006.

16. Forthofer RN, Lee ES, Hernandez M: Contingency Table Analysis. Biostatistics: A Guide to Design, Analysis and Discovery 2007. Academic Press, Elsevier, Burlington, Mass, USA, $2^{\text {nd }}$ edition, 437-440.

17. Taylor AE, Ebrahim S, Ben-Shlomo Y, Martin RM, Whincup PH, Yarnell JW, Wannamethee SG and Lawlor DA: Comparison of the associations of body mass index and measures of central adiposity and fat mass with coronary heart disease, diabetes, and all-cause mortality: a study using data from 4 UK cohorts. Am J Clin Nutr 2010, 91:547-56. | Article I PubMed

18. MacKay MF, Haffner SM, Wagenknecht LE, D’Agostino RB, Jr. and Hanley AJ: Prediction of type $\mathbf{2}$ diabetes using alternate anthropometric measures in a multi-ethnic cohort: the insulin resistance atherosclerosis study. Diabetes Care 2009, 32:956-8. | Article | PubMed Abstract I PubMed Full Text

19. Misra A, Wasir JS and Vikram NK: Waist circumference criteria for the diagnosis of abdominal obesity are not applicable uniformly to all populations and ethnic groups. Nutrition 2005, 21:969-76. | Article | PubMed

20. Schubert CM, Rogers NL, Remsberg KE, Sun SS, Chumlea WC, Demerath EW, Czerwinski SA, Towne B and Siervogel RM: Lipids, lipoproteins, lifestyle, adiposity and fat-free mass during middle age: the Fels Longitudinal Study. Int J Obes (Lond) 2006, 30:251-60. | Article | PubMed

21. Snijder MB, van Dam RM, Visser M and Seidell JC: What aspects of body fat are particularly hazardous and how do we measure them? Int J Epidemiol 2006, 35:83-92. | Article | PubMed

22. Donahue RP, Abbott RD, Bloom E, Reed DM and Yano K: Central obesity and coronary heart disease in men. Lancet 1987, 1:821-4. | Article | PubMed
23. Misra A, Madhavan M, Vikram NK, Pandey RM, Dhingra V and Luthra K: Simple anthropometric measures identify fasting hyperinsulinemia and clustering of cardiovascular risk factors in Asian Indian adolescents. Metabolism 2006, 55:1569-73. I Article I PubMed

24. Sievenpiper JL, Jenkins DJ, Josse RG, Leiter LA and Vuksan V: Simple skinfold-thickness measurements complement conventional anthropometric assessments in predicting glucose tolerance. Am J Clin Nutr 2001, 73:567-73. | Article | PubMed

25. Mensink M, Feskens EJ, Kruijshoop M, de Bruin TW, Saris WH and Blaak EE: Subscapular skinfold thickness distinguishes between transient and persistent impaired glucose tolerance: Study on LifestyleIntervention and Impaired Glucose Tolerance Maastricht (SLIM). Diabet Med 2003, 20:552-7. I Article I PubMed

26. Tanaka S, Togashi K, Rankinen T, Perusse L, Leon AS, Rao DC, Skinner JS, Wilmore JH, Despres JP and Bouchard C: Sex differences in the relationships of abdominal fat to cardiovascular disease risk among normal-weight white subjects. Int J Obes Relat Metab Disord 2004, 28:320-3. | Article | PubMed

27. Kim JY, Han SH and Yang BM: Implication of high-body-fat percentage on cardiometabolic risk in middle-aged, healthy, normal-weight adults. Obesity (Silver Spring) 2012. | Article | PubMed

28. Randall OS, Retta TM, Kwagyan J, Gordeuk VR, Xu S, Maqbool AR, Ketete $\mathrm{M}$ and Obisesan TO: Obese African Americans: the prevalence of dyslipidemia, hypertension, and diabetes mellitus. Ethn Dis 2004 , 14:384-8. | PubMed

29. Hoenig MR: Implications of the obesity epidemic for lipid-lowering therapy: non-HDL cholesterol should replace LDL cholesterol as the primary therapeutic target. Vasc Health Risk Manag 2008, 4:143-56. | Article | PubMed Abstract | PubMed Full Text

30. Misra A, Luthra K and Vikram NK: Dyslipidemia in Asian Indians: determinants and significance. J Assoc Physicians India 2004, 52:13742. | Pdf | PubMed

\section{Citation:}

Vaccaro J A and Huffman F G: Obesity indicators by race/ethnicity for diagnosis of cardiometabolic diseases for a US representative sample of adults. Cardiovascular System 2013, 1:4. http://dx.doi.org/10.7243/2052-4358-1-4 